\title{
Association between educational level and vegetable use in nine European countries
}

\author{
Ritva Prättälä ${ }^{1, \star}+$, Samu Hakala ${ }^{1}$, Albert-Jan R Roskam ${ }^{2}$, Eva Roos ${ }^{3}$, Uwe Helmert ${ }^{4}$, \\ Jurate Klumbiene ${ }^{5}$, Herman Van Oyen ${ }^{6}$, Enrique Regidor ${ }^{7}$ and Anton E Kunst ${ }^{2}$ \\ ${ }^{1}$ National Public Health Institute, Helsinki, Finland: ${ }^{2}$ Department of Public Health, Erasmus MC, Rotterdam, The \\ Netherlands: ${ }^{3}$ Folkhälsan Research Center, Helsinki, Finland: ${ }^{4}$ Center for Social Policy Research, University of \\ Bremen, Bremen, Germany: ${ }^{5}$ Kaunas University of Medicine, Kaunas, Lithuania: ${ }^{6}$ Unit of Epidemiology, Scientific \\ Institute of Public Health, Brussels, Belgium: ${ }^{7}$ Department of Preventive Medicine and Public Health, Universidad \\ Complutense de Madrid, Madrid, Spain
}

Submitted 2 April 2008: Accepted 10 February 2009: First published online 30 April 2009

\begin{abstract}
Objective: The relationship of socio-economic status and vegetable consumption is examined in nine European countries. The aim is to analyse whether the pattern of socio-economic variation with regard to vegetable consumption is similar in all studied countries with high $v$. low vegetable availability and affordability, and whether education has an independent effect on vegetable consumption once the effects of other socio-economic factors have been taken into account. Design: The data for the study were obtained from national surveys conducted in Finland, Denmark, Germany, Estonia, Latvia, Lithuania, France, Italy and Spain, in 1998 or later. These surveys included data on the frequency of use of vegetables. Food Balance Sheets indicated that the availability of vegetables was best in the Mediterranean countries. The prices of vegetables were lowest in the Mediterranean countries and Germany.

Results: Educational level was positively associated with vegetable consumption in the Nordic and Baltic countries. In the Mediterranean countries, education was not directly associated with the use of vegetables but, after adjusting for place of residence and occupation, it was found that those with a lower educational level consumed vegetables slightly more often. Manual workers consumed vegetables less often than non-manual workers, but otherwise there was no systematic association with occupation.

Conclusions: The Mediterranean countries did not show a positive association between educational level and vegetable consumption. The positive association found in the Northern European countries is linked to the lower availability and affordability of vegetables there and their everyday cooking habits with no long-standing cultural tradition of using vegetables.
\end{abstract}

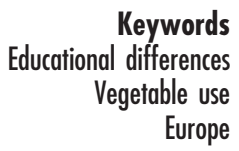

Socio-economic differences in the consumption of vegetables have been demonstrated in several European countries $^{(1,2)}$. People with a higher educational level or in higher occupational status groups generally eat vegetables more often than those in lower socio-economic groups.

Socio-economic differences with regard to vegetable consumption are in line with those observed in relation to overweight, obesity $^{(3,4)}$ and $\mathrm{CVD}^{(5)}$. In the Nordic countries and in England and Wales, half or more of the socioeconomic gap in total mortality is due to an excess risk of CVD in the lower socio-economic groups. In France,

$\dagger$ Correspondence address: National Institute for Health and Welfare, PO 30, FI-00271 Helsinki, Finland.
Switzerland, Italy, Spain and Portugal, however, CVD account for a small fraction of the higher risks of premature mortality ${ }^{(5-7)}$. Multivariate explanatory studies have nevertheless provided direct evidence of the contribution of vegetable consumption to observed socioeconomic differences in all-cause and cardiovascular mortality $^{(8)}$.

Diet, like other health behaviours, has been assumed to function as a specific determinant mediating the effect of socio-economic position on health ${ }^{(7)}$. According to this assumption people belonging to higher socio-economic groups follow a healthier diet, and thus more often avoid overweight and other risks of chronic disease. In the lower socio-economic groups people may have less 
money to buy healthy food, have poorer access to shops offering a good variety of fruit and vegetables, and may be less motivated to maintain a healthy $\operatorname{diet}^{(9)}$.

Previous studies in Europe have mainly analysed socioeconomic differences in food habits within a single country at a time ${ }^{(10-13)}$. However, there are two systematic reviews based on published reports from fifteen European countries $^{(1,2)}$ and one review that also covers North American and Australian studies ${ }^{(14)}$. The studies included in the reviews used different designs and methods. Some of them were based on nationally representative samples of individuals, while others were conducted only within selected regions or used entire households as their sampling unit. These previous studies have demonstrated a link between education and occupation and the consumption of vegetables: in most countries, people with a higher educational level or higher occupational status consumed vegetables more often.

The previous European studies have not been able to analyse the relative importance of both education and occupation as determinants of vegetable consumption because they have typically included only one indicator of socio-economic status, usually education. However, as education and occupation have mutual causal interdependencies, it may be important to include both measures in the analyses (see e.g. reference 15).

The present paper is based on secondary analyses of national health surveys from nine European countries. The countries were selected to represent both Northern and Southern Europe. Educational and occupational differences are compared between the countries, and place of residence is also included because the availability of vegetables may be different in rural and urban areas and place of residence may be associated with socioeconomic status. Following the study by Roos et al. (2), which suggested that socio-economic differences in the consumption of vegetables were more systematic in Northern Europe than in Spain and Greece, where the availability of vegetables was good, we have made the assumption that educational level differences are larger in countries where vegetables are poorly available and where their affordability is low, i.e. their prices are high.

The study questions are:

1. Do the Northern countries differ from the Southern European countries with regard to availability and affordability of vegetables?

2. Is the pattern of socio-economic variation with regard to consumption of vegetables similar in all the European countries studied?

3. Does educational level have an independent effect on vegetable consumption once the effects of occupational status and place of residence have been taken into account?

4. Do countries showing a high general level of vegetable availability and affordability demonstrate less consistency in the relationship between education or occupation and vegetable consumption than countries with a low availability and affordability?

\section{Methods}

\section{Estimating availability and affordability of vegetables}

The availability of vegetables in the countries studied was estimated on the basis of the FAO Food Balance Sheets ${ }^{(16)}$. The Food Balance Sheets present figures that are based on national statistics about production, export and import of various food groups. They take into account vegetables produced to feed animals but not waste in consumption. They give the annual per capita amount of vegetables available for human consumption but do not show how much was actually consumed. The countries in the study were classified into groups based on high and low availability of vegetables. The trends from 1993 to 2003 were compared in order to find out whether the supply of vegetables was increasing or not.

Affordability refers to the relative prices of vegetables. Price levels in the countries studied can be compared using the Eurostat Comparative Price Level Index (PLI) for vegetables. Eurostat also publishes a volume index of Gross Domestic Product (GDP) per capita, which measures economic activity and can be used to estimate purchasing power in different countries. In order to compare vegetable prices in the countries studied, and taking purchasing power into account, we used figures obtained by dividing the PLI by per capita GDP ${ }^{(17)}$. Both the PLI and GDP figures were available for the year 2001.

\section{National bealth surveys}

The study data were obtained from nine European health surveys conducted in 1998-2004 and identified in the EUROTHINE project ${ }^{(18)}$. All of the surveys were based on nationally representative samples. The response rates in the studies were mostly satisfactory, the lowest rates being in Estonia (61-67\%). Micro data sets from each national survey were submitted to the coordination centre of the EUROTHINE project ${ }^{(19)}$.

The coordination centre first harmonised the data sets delivered from individual countries and then compared the available information for each variable, identified any inconsistencies and constructed common measures applicable to the maximum number of countries. All common variables were judged for their degree of comparability. This confirmed that the variables of the present study can be used to compare the countries with respect to the general association between the selected health and socio-economic variables.

For inclusion in the present study, the data set from each national survey had to fulfil certain criteria. Its variables had to include the frequency of use of vegetables and 
Table 1 Overview of national surveys included in the present analysis

\begin{tabular}{lrcll}
\hline Country & $n$ & Response rate $(\%)$ & \multicolumn{1}{c}{ Study years } & \\
\hline Finland & 9940 & $65-69$ & $2000,2002,2004$ & Furvey \\
Denmark & 16690 & 74 & 2000 & Danish Health and Morbidity Survey 2000 \\
Germany & 7124 & 61 & 1998 & German National Health Examination and Interview Survey \\
Estonia & 4378 & $61-67$ & 2002,2004 & Finbalt Health Monitor \\
Latvia & 6166 & $60-68$ & $2000,2002,2004$ & Finbalt Health Monitor \\
Lithuania & 5888 & $61-73$ & $2000,2002,2004$ & Finbalt Health Monitor \\
France & 13771 & $70^{*}$ & 2004 & Health, Health Care and Insurance Survey \\
Italy & 167618 & $82-87^{*}$ & 1999,2000 & Health and Health Care Utilization 1999-2000 \\
Spain & 20748 & 85 & 2001 & Multipurpose Family Survey 2000 \\
\hline
\end{tabular}

${ }^{\star}$ Response rate of households.

a set of independent variables comprising sex, age, education, occupation and place of residence, and the year of data collection had to be 1998 or later. The national surveys meeting these criteria were those from Denmark, Estonia, Finland, France, Germany, Italy, Latvia, Lithuania and Spain. The data sets for Estonia, Finland, Lithuania and Latvia are each from a continuous series of repeated cross-sectional surveys, and so these were combined into four larger data files covering the period from 2000 to 2004. The characteristics of the surveys are presented in Table 1.

\section{Dependent variable}

Vegetable consumption was measured as frequency of use. This was the most common and comparable vegetable-related variable in the surveys. In order to improve the comparability of the data, a dichotomous variable, ' $1=$ daily (incl. almost daily)' and ' $0=$ not daily', was used in the statistical analyses. The category 'not daily' included 'three to five times per week', 'once or twice per week' and 'never or almost never'. The Danish, Finnish, Latvian, Lithuanian and German surveys included separate questions for fresh (raw) and non-fresh (boiled or preserved) vegetables. In these surveys a combined variable with the corresponding classes was created, in which the category 'daily' included those who used either type of vegetables daily or both types at least three times per week. In Estonia, the question included only fresh (raw) vegetables. The Estonian data were included in the comparison because data from other countries having both vegetable questions showed that the gender and socio-economic patterns were similar for both fresh and all vegetables.

\section{Independent variables and confounders}

The independent variables in the present study were place of residence, occupational class and educational level. Age and sex were considered as confounders. Only subjects who were 20 to 64 years of age were included in this study. Age was grouped into 5-year intervals: 20-24, and so on, up to 60-64 years.

The place of residence variable measures the degree of urbanisation of the residential location of the respondent. We distinguish two broad categories: urban and rural areas. Urban areas include major metropolitan areas and cities with more than 50000 inhabitants, while rural areas include sparsely populated areas and settlements of up 50000 inhabitants.

The education variable refers to the level of education, which was available in comparable form for all the countries. Educational level was classified into four categories under the International Standard Classification of Education (ISCED). The categories were: ' $1=$ no or primary education' (ISCED 1), '2 = lower secondary' (ISCED 2), ' 3 = upper secondary and post-secondary non-tertiary' $($ ISCED $3+4)$ and ' $4=$ tertiary education' (ISCED $5+6$ ).

Occupational class consists of four categories: nonmanual (upper non-manual and lower non-manual), manual (skilled manual workers and unskilled, routine workers), self-employed and other. The last of these categories included unemployed persons, housewives, retirees and those who could not be classified on the basis of their last occupation. The original finer classifications of the manual and non-manual occupations given above in parentheses were reclassified into the two categories of non-manual and manual to improve comparability of the data. Comparison of the differences between occupational groups is more complicated than comparison of educational differences, because the categories 'self-employed' and 'others' are very heterogeneous. Therefore, our commentary on occupational groups is confined to the differences between the manual and non-manual groups, and the manual occupation is used as the reference category. The other occupational groups were nevertheless included in the analyses, and the results concerning these are shown in the tables.

\section{Statistical analysis}

The dependent variable 'daily use of vegetables' was modelled using logistic regression analysis. The models were estimated separately for each country. The data were adjusted for age using the 5-year age groups in all models. The variables were fitted to the models according to their assumed chronological order: education, place of residence and occupation.

All the analyses were first carried out separately for men and women. The preliminary analyses showed that 
Table 2 Distribution of respondents by gender, use of vegetables and socio-economic measures in the national surveys

\begin{tabular}{|c|c|c|c|c|c|c|c|}
\hline \multirow[b]{2}{*}{ Country } & & \multirow[b]{2}{*}{$n$} & \multirow{2}{*}{$\frac{\text { Vegetables }}{\text { Daily }(\%)}$} & \multirow{2}{*}{$\frac{\text { Education }}{\text { High (\%) }}$} & \multirow{2}{*}{$\frac{\text { Place of residence }}{\text { Urban }(\%)}$} & \multicolumn{2}{|c|}{ Occupation } \\
\hline & & & & & & Manual (\%) & Non-manual (\%) \\
\hline \multirow[t]{3}{*}{ Finland } & Men & 4035 & $39 \cdot 1$ & $20 \cdot 7$ & $40 \cdot 4$ & $23 \cdot 5$ & $39 \cdot 2$ \\
\hline & Women & 4908 & $59 \cdot 1$ & $26 \cdot 0$ & $43 \cdot 6$ & $26 \cdot 2$ & $57 \cdot 3$ \\
\hline & Total & 8943 & $50 \cdot 1$ & $23 \cdot 6$ & $42 \cdot 2$ & $25 \cdot 0$ & $49 \cdot 1$ \\
\hline \multirow[t]{3}{*}{ Denmark } & Men & 6293 & $35 \cdot 1$ & $20 \cdot 6$ & $38 \cdot 8$ & $26 \cdot 0$ & $41 \cdot 2$ \\
\hline & Women & 6349 & $52 \cdot 2$ & $22 \cdot 8$ & $38 \cdot 4$ & $14 \cdot 0$ & $49 \cdot \overline{9}$ \\
\hline & Total & 12642 & $43 \cdot 7$ & $21 \cdot 7$ & $38 \cdot 6$ & $19 \cdot 9$ & $45 \cdot 6$ \\
\hline \multirow[t]{3}{*}{ Germany } & Men & 2792 & $29 \cdot 7$ & $19 \cdot 1$ & $36 \cdot 3$ & 43.5 & $38 \cdot 0$ \\
\hline & Women & 2903 & $43 \cdot 3$ & $11 \cdot 6$ & $38 \cdot 0$ & $24 \cdot 5$ & 61.9 \\
\hline & Total & 5695 & $36 \cdot 6$ & $15 \cdot 3$ & $37 \cdot 2$ & $33 \cdot 8$ & $50 \cdot 2$ \\
\hline \multirow[t]{3}{*}{ Estonia* } & Men & 1521 & $16 \cdot 1$ & $20 \cdot 9$ & $64 \cdot 2$ & $42 \cdot 1$ & $26 \cdot 1$ \\
\hline & Women & 2180 & $25 \cdot 0$ & $31 \cdot 1$ & $68 \cdot 2$ & $9 \cdot 7$ & $54 \cdot 0$ \\
\hline & Total & 3701 & $21 \cdot 3$ & $26 \cdot 9$ & $66 \cdot 6$ & $23 \cdot 0$ & $42 \cdot 6$ \\
\hline \multirow[t]{3}{*}{ Latvia } & Men & 2059 & $23 \cdot 9$ & $19 \cdot 9$ & $44 \cdot 8$ & $31 \cdot 8$ & $21 \cdot 2$ \\
\hline & Women & 2928 & $32 \cdot 8$ & $28 \cdot 5$ & $49 \cdot 7$ & $7 \cdot 4$ & $46 \cdot 7$ \\
\hline & Total & 4987 & $29 \cdot 1$ & $24 \cdot 9$ & $47 \cdot 7$ & $17 \cdot 5$ & $36 \cdot 2$ \\
\hline \multirow[t]{3}{*}{ Lithuania } & Men & 2429 & $27 \cdot 5$ & $18 \cdot 6$ & $43 \cdot 8$ & $30 \cdot 7$ & $31 \cdot 7$ \\
\hline & Women & 3102 & $33 \cdot 4$ & $23 \cdot 1$ & $47 \cdot 2$ & $10 \cdot 5$ & $52 \cdot 8$ \\
\hline & Total & 5531 & $30 \cdot 8$ & $21 \cdot 1$ & $45 \cdot 7$ & $19 \cdot 4$ & $43 \cdot 5$ \\
\hline \multirow[t]{3}{*}{ France } & Men & 4419 & $33 \cdot 6$ & $32 \cdot 7$ & $45 \cdot 4$ & $38 \cdot 6$ & $45 \cdot 0$ \\
\hline & Women & 4711 & $44 \cdot 9$ & $36 \cdot 1$ & $46 \cdot 9$ & $12 \cdot 0$ & $74 \cdot 4$ \\
\hline & Total & 9130 & $39 \cdot 4$ & $34 \cdot 5$ & $46 \cdot 2$ & $24 \cdot 9$ & $60 \cdot 2$ \\
\hline \multirow[t]{3}{*}{ Italy } & Men & 17524 & $30 \cdot 1$ & $8 \cdot 7$ & $36 \cdot 1$ & $27 \cdot 6$ & $32 \cdot \overline{5}$ \\
\hline & Women & 18059 & $38 \cdot 7$ & $8 \cdot 7$ & $37 \cdot 1$ & $12 \cdot 6$ & $25 \cdot 5$ \\
\hline & Total & 35583 & $34 \cdot 4$ & $8 \cdot 7$ & $36 \cdot 6$ & $20 \cdot 0$ & $29 \cdot 0$ \\
\hline \multirow[t]{3}{*}{ Spain } & Men & 7416 & $24 \cdot 7$ & $17 \cdot 7$ & $48 \cdot 4$ & $55 \cdot 1$ & $20 \cdot 3$ \\
\hline & Women & 7535 & $36 \cdot 9$ & $16 \cdot 3$ & $48 \cdot 9$ & $44 \cdot 5$ & $14 \cdot 8$ \\
\hline & Total & 14951 & $30 \cdot 9$ & $17 \cdot 0$ & $48 \cdot 6$ & $49 \cdot 8$ & $17 \cdot 5$ \\
\hline
\end{tabular}

*The Estonian data included only raw vegetables.

the socio-economic patterns of vegetable use were similar among men and women. In order to increase the statistical power of the models, men and women were therefore combined in the logistic regression analyses, and the analyses were adjusted for sex, without sex interaction. The differences between men and women are shown only in the descriptive table on the proportions of daily users in each of the countries (Table 2).

The first three models included only one socio-economic variable at a time, and are termed the 'main effect models'. As the purpose was to examine the independent effect of education once the effects of place of residence or occupation have been taken into account, the second set of models included educational level plus either place of residence or occupation; these are termed the 'pairwise models'. The 'final models' included all three socio-economic variables adjusted for each other.

For each explanatory variable, differences are presented as gender- and age-adjusted odds ratios and their 95\% confidence intervals. The lowest educational level, rural place of residence and manual occupational class were used as reference categories.

The educational distributions of the national surveys varied; for example, in Italy $8.5 \%$ of respondents belonged to the highest educational group but in France, $34.5 \%$. Therefore, it was necessary to take into account the population size of each educational group. This was done by constructing a ranking measure for educational level and utilising this in the calculation of a Relative
Inequality Index (RII) for the use of vegetables. The ranked variable gives stepwise-increasing educational categories with values between and including 0 (lowest) and 1 (highest) ${ }^{(19)}$. The RII is a regression-based measure that assesses the association between the cumulative ratios of daily vegetable users and the relative position of each educational group (see e.g. reference 20). The relative position is measured as the cumulative proportion of each educational group within the educational hierarchy, with 0 and 1 as extreme values. The RII can be interpreted as the odds of being a daily user of vegetables at the very top of the educational hierarchy as compared with the very lowest end of the educational hierarchy. The outcome measures can be compared between countries, provided that a detailed and hierarchical classification of educational level is used in each country. For the current paper the RII was estimated using logistic regression controlled for sex and age. We also present the RII for education adjusted for place of residence and/or occupational class.

\section{Results}

\section{Availability of vegetables in 1993-2003 and prices of vegetables in 2001}

The annual per capita availability of vegetables is presented in Fig. 1. The Southern European countries, i.e. France, Italy and Spain, show high availability - over 


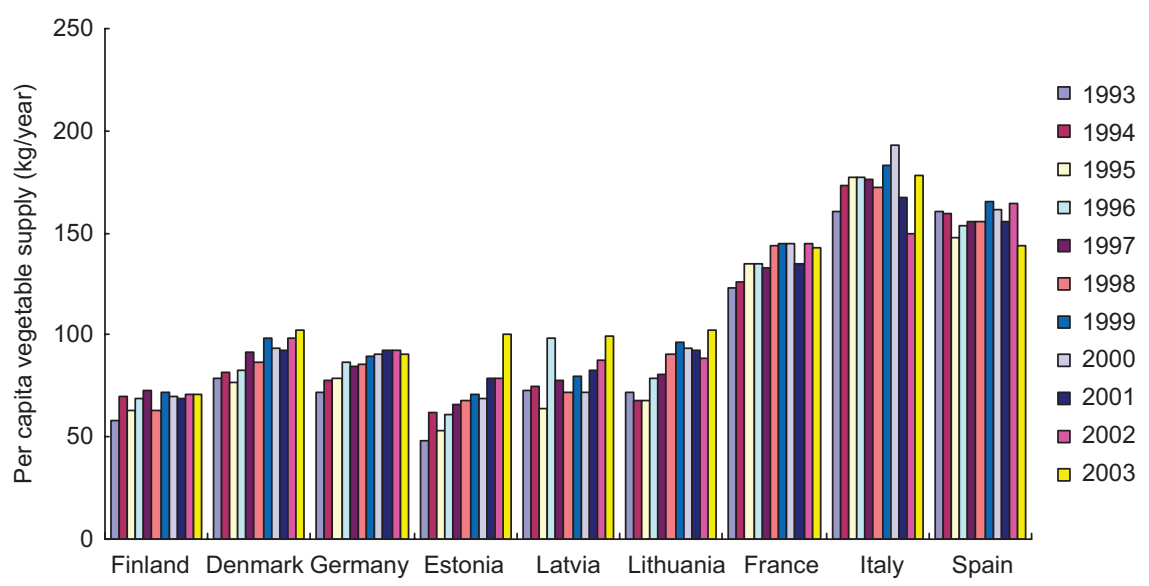

Fig. 1 Trends in the per capita supply of vegetables 1993-2003 (kg/year) in the countries studied ${ }^{(16)}$

Table 3 Comparative Price Level Index (PLI) for vegetables divided by volume index of Gross Domestic Product (GDP) per capita, 2001

\begin{tabular}{|c|c|c|c|c|c|}
\hline Northern/Central Europe & PLI/GDP & Baltic countries & PLI/GDP & Southern Europe & PLI/GDP \\
\hline Finland & $1 \cdot 02$ & Estonia & 1.64 & France & 0.97 \\
\hline Denmark & $1 \cdot 12$ & Latvia & 1.62 & Italy & 0.85 \\
\hline Germany & 0.86 & Lithuania & 1.54 & Spain & 0.82 \\
\hline
\end{tabular}

$\mathrm{EU} 27=1 \cdot 00$ for both PLI and GDP.

$100 \mathrm{~kg}$ per capita per annum in 1993 - and small changes in availability over time. In Finland, Denmark, Germany and the Baltic countries, the availability of vegetables is much lower - between 68 and $86 \mathrm{~kg}$ per capita per annum. However, all these countries show a larger increase in availability than the Southern European countries. All in all, the Food Balance Sheets from 1993 to 2003 support the assumption that vegetable consumption in the Mediterranean countries is traditionally high, while in the other European countries it is lower but increasing.

The price levels of vegetables are presented in Table 3. Values above 1.00 suggest that the prices of vegetables are higher than elsewhere in the European Union when purchasing power is taken into account. This is the case for the Baltic countries. On the other hand, values below 1.00 imply that vegetables are relatively cheaper than elsewhere, as is the case for Germany, Italy, France and Spain.

\section{Prevalence of daily use of vegetables by place of residence and socio-economic status}

Educational level was associated with daily use of vegetables in all countries except Germany. In the Nordic and Baltic countries those with the highest educational level were more often daily users of vegetables, while in France, Italy and Spain, the group with lowest educational level used vegetables more often than the other groups (Table 4). The figures presenting percentages of daily users in the four educational level groups are in line with the RII for vegetable consumption based on the ranked educational variable. Even in Germany, where the differences between educational groups did not reach statistical significance, the RII is above 1, which indicates that groups with higher educational level consume vegetables more often than other groups. In France, Italy and Spain, the RII did not deviate significantly from 1 (Table 5).

Urban respondents were more often daily users of vegetables in Denmark, Finland, Estonia, Latvia, Lithuania and Italy; although in Italy the urban/rural difference barely achieved statistical significance. In France, Germany and Spain, vegetable consumption did not vary by place of residence. The differences between urban and rural areas were largest in Estonia and Latvia (Table 4).

Daily use of vegetables was more common in the nonmanual than the manual group in all countries studied (Table 4). The differences in vegetable consumption between manual and non-manual workers were somewhat smaller in Spain and Italy than in the other countries. The direction of the difference between manual workers and self-employed respondents was varied among the countries. In France, Spain, Italy, Germany and Denmark, the self-employed were more often daily users than the manual workers, while in Finland and the Baltic countries the reverse was true.

\section{Independent effects of education, place of residence and occupation on the daily use of vegetables}

According to the pairwise models incorporating education and place of residence, but not occupation, the effect of education diminished when place of residence was taken into account. In Denmark, Finland, Estonia, Latvia and Lithuania, the effect of education nevertheless 


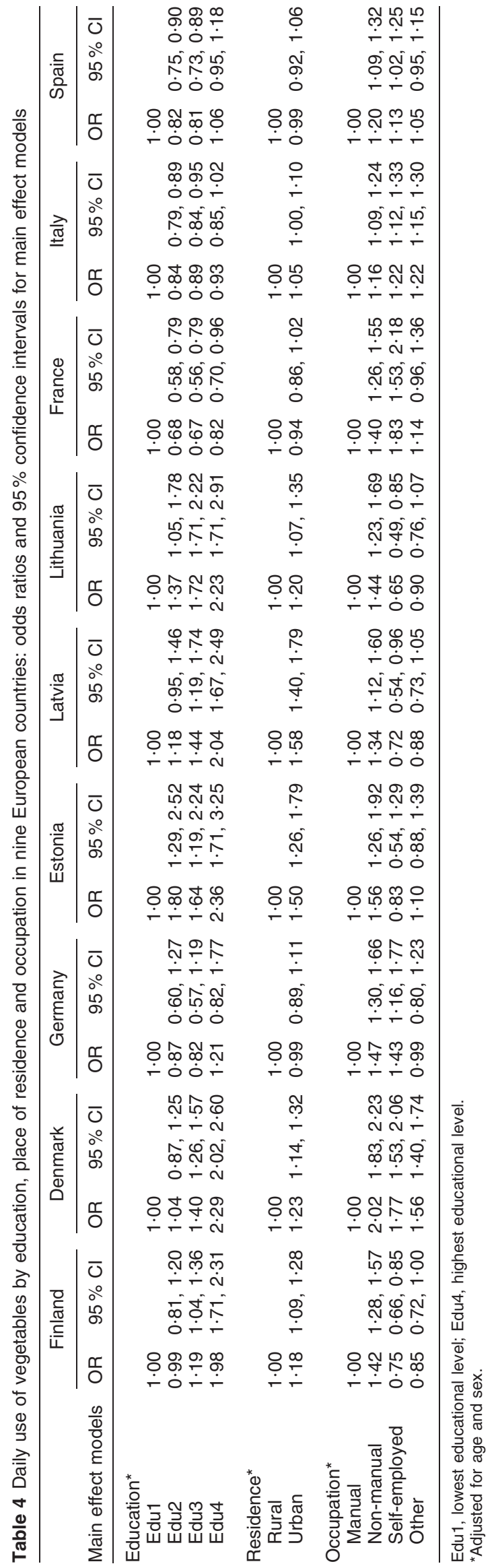

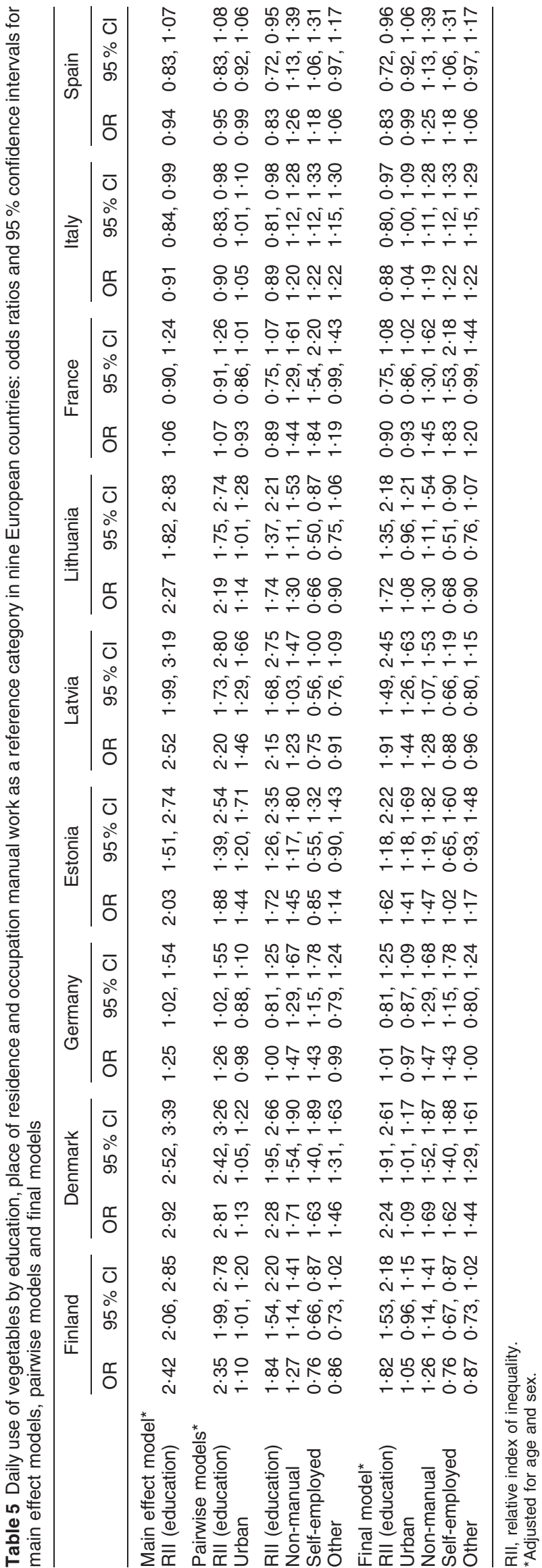


remained significant. In Germany the weak effect of education remained unchanged (Table 5).

Adding occupation into the model diminished somewhat the effect of education (Table 5). The pairwise models showed similar but weaker associations between each socio-economic measure and vegetable consumption than the non-adjusted main effect models including only one socio-economic variable at a time.

Finally, education, place of residence and occupation were all included in the model at the same time. Educational level had an independent effect on the consumption of vegetables in Denmark, Finland, Estonia, Latvia and Lithuania. In Germany, the effect of education was attenuated after adjusting for the other socio-economic variables. In France, Italy and Spain, those with a lower educational level used vegetables more often, even though in France the difference did not reach statistical significance (Table 5).

According to the final models, place of residence had an independent effect on vegetable consumption only in Denmark, Estonia and Latvia: people living in urban areas were more often daily users of vegetables regardless of their socio-economic status. When manual occupation was used as a reference category, having a non-manual occupation was independently associated with the daily use of vegetables in all countries (Table 5). Differences between manual workers and the self-employed or other occupational groups were non-systematic and difficult to interpret.

\section{Discussion}

The results of the present analysis, based on national surveys conducted in Europe between 1998 and 2004, indicate that the pattern of socio-economic variation with regard to consumption of vegetables was not similar in every country. The most obvious difference was observed between the Mediterranean and the Northern European countries with respect to educational differences. In France, Spain and Italy, educational level had a weak effect on the use of vegetables: after adjusting for place of residence and occupation, those having a higher educational level were found to consume vegetables slightly less often than those with a lower educational level. In the Nordic and Baltic countries, the educational differences were greater and the direction of their association was different: those with a higher educational level were more often daily users of vegetables. The effect remained even after adjustment for place of residence or occupation. In Germany, vegetable use did not vary with educational level.

Compared with previous international overviews in this field, the present study has improved the comparability of estimates by acquiring, harmonising and reanalysing micro data sets from several countries. Moreover, we excluded surveys that were conducted before 1998 and those with a response rate of below $60 \%$. We also utilised the previous judgements of comparability carried out by the EUROTHINE project coordination centre ${ }^{(19)}$ and did not accept variables that could not be used to compare the countries with respect to general association between the outcome and explanatory variables. To improve the comparability of the results we took into account the between-country variation in the educational distributions and also used, in addition to the standard classification of education (ISCED), a ranking measure of educational level, the RII.

However, there are methodological limitations that need to be considered when interpreting the results. The data sets are based on national health surveys conducted at different times around the turn of the millennium. The data collection methods were either self-administered questionnaire or face-to-face-interview. All of the surveys focused on health and risk factors, but the context for sociodemographic and behavioural questions varied. In addition, the questions concerning the frequency of eating vegetables did not require information on the quantity of vegetables consumed.

The figures on the proportions of daily users based on the survey data were not in line with the availability figures given in the FAO Food Balance Sheets for the countries in question. The discrepancy is understandable in view of the differences between the data collection methods. It also highlights the fact that the survey questions dealt only with behavioural frequencies and did not provide quantitative estimates of vegetable consumption. Neither the statistical availability data nor the survey data on frequency of use indicate the amount really consumed. Trends obtained from the Food Balance Sheets and from the few repeated national surveys are nevertheless in accordance $e^{(13,21)}$.

The simple frequency questions analysed in the present study can be understood as indicators of a generally recommendable diet. On the basis of these frequencies the respondents can be roughly categorised into two groups: high $v$. low users of vegetables. Despite the methodological limitations, our results concerning the associations of gender or education with vegetable consumption in the individual countries are not contradictory with more detailed dietary surveys from the same countries ${ }^{(10,14,22-25)}$. Simple frequency questionnaires can be used to estimate differences between populations or trends over time ${ }^{(26,27)}$. We are therefore satisfied that our data can be used to compare the patterns of socio-economic differences with regard to vegetable consumption among the countries studied, thus meeting the purpose of our study.

Our results support the assumption that a positive association between educational level and vegetable consumption is related to the availability of vegetables. The positive association is observed in countries with a low availability and high prices (Nordic and Baltic countries), as compared with countries where the availability and affordability are 
higher (France, Italy, Spain). In the latter countries a weak but opposite association is observed. The fact that the socioeconomic patterns in Germany are somewhere between those of the Southern and Northern countries could be due to the low vegetable prices in Germany. In France, Spain and Italy, availability has been high and stable during the last decade, whereas in the countries with a lower availability the trend has been one of increasing availability. Furthermore, the result that vegetable consumption was similar in both rural and urban areas in Germany, France, Spain and Italy, but not in Denmark, Finland and the Baltic countries, might be associated with the availability of vegetables. Urban dwellers in Northern Europe consume more vegetables because of greater availability throughout the year as compared with rural areas.

Availability and affordability cannot be the only explanations for the varying educational patterns concerning vegetable consumption. Cultural factors expressed in dietary traditions can also have an impact. Vegetables are essential components of the so-called Mediterranean diet. In the Mediterranean countries, local production of fruit and vegetables has a long history. Local products were available throughout the year ${ }^{(28)}$, and therefore even the lower socio-economic groups could adapt them as an essential part of everyday cooking. In Northern Europe, vegetables were available only during summer, while in spring and winter imported products would occasionally be available but at a very high price. Therefore, Northern Europeans have not developed a tradition of using vegetables on a daily basis. When new foods entered the market, the higher socioeconomic groups were the first to buy them and to adopt modern food habits. This is the case in Finland, for example, where those with a higher educational level have set the trend regarding regular use of vegetables and low-fat milk products ${ }^{(29,30)}$.

To conclude, the positive association between educational level and vegetable consumption is more consistent in countries where their availability and affordability are poor and where the use of vegetables in everyday cooking has not been a long-standing cultural tradition. In order to increase the use of vegetables among the lower socioeconomic groups in Northern Europe, it is important to improve the availability and affordability of vegetables.

\section{Acknowledgements}

The preparation of this paper was funded by the Academy of Finland (grant 214126, 15/12/2005), the Public Health Program of the European Commission (grant 2003125) and the Finnish National Public Health Institute (KTL). There are no conflicts of interest. R.P. planned the design and prepared the manuscript. All authors commented and added to the manuscript versions and checked the results and interpretations concerning their own country. In addition, the following authors completed specific tasks: S.H. carried out the statistical analyses; A.-J.R.R. and A.E.K. acquired and edited the study data, harmonised the socio-economic and behavioural variables and judged their comparability; E.R. contributed to the specification of study questions, to the identification of previous studies and to the choice of the most reliable variables; H.V.O. and A.E.K. contributed to the statistical analyses and the study design.

\section{References}

1. Irala-Estevez JD, Groth M, Johansson L, Oltersdorf U, Prättälä R \& Martínez-González MA (2000) A systematic review of socio-economic differences in food habits in Europe: consumption of fruit and vegetables. Eur J Clin Nutr 54, 706-714.

2. Roos G, Johansson L, Kasmel A, Klumbiené J \& Prättälä R (2001) Disparities in vegetable and fruit consumption: European cases from the north to the south. Public Health Nutr 4, 35-43.

3. Klumbiene J, Petkeviciene J, Helasoja V, Prättälä R \& Kasmel A (2004) Sociodemographic and health behaviour factors associated with obesity in adult populations in Estonia, Finland and Lithuania. Eur J Public Health 14, 390-394.

4. Molarius A, Seidell JC, Sans S, Tuomilehto J \& Kuulasmaa K (2000) Educational level, relative body weight, and changes in their association over 10 years: an international perspective from the WHO MONICA Project. Am J Public Health 90, 1260-1268.

5. Kunst AE, Groenhof F, Andersen O et al. (1999) Occupational class and ischemic heart disease mortality in the United States and 11 European countries. Am J Public Health 89, 47-53.

6. Kunst AE, Groenhof F, Mackenbach JP \& Health EW (1998) Occupational class and cause specific mortality in middle aged men in 11 European countries: comparison of population based studies. EU Working Group on Socioeconomic Inequalities in Health. BMJ 316, 1636-1642.

7. Mackenbach J, Bakker M, Kunst A \& Didericksen F (2002) Socioeconomic inequalities in health in Europe. In Reducing Inequalities in Health: A European Perspective, pp. 3-24 [J Mackenbach and M Bakker, editors]. London/ New York: Routledge.

8. Laaksonen M, Talala K, Martelin T, Rahkonen O, Roos E, Helakorpi S, Laatikainen T \& Prättälä R (2008) Health behaviours as explanations for educational level differences in cardiovascular and all-cause mortality: a follow-up of 60000 men and women over 23 years. Eur J Public Health 18, 38-43.

9. Dowler E (2001) Inequalities in diet and physical activity in Europe. Public Health Nutr 4, 701-709.

10. Groth MV, Fagt S \& Brondsted L (2001) Social determinants of dietary habits in Denmark. Eur J Clin Nutr 55, 959-966.

11. Helmert U, Mielck A \& Shea S (1997) Poverty, health, and nutrition in Germany. Rev Environ Health 12, 159-170.

12. Laaksonen M, Prattala R, Helasoja V, Uutela A \& Lahelma E (2003) Income and health behaviours. Evidence from monitoring surveys among Finnish adults. J Epidemiol Community Health 57, 711-717.

13. Roos E, Talala K, Laaksonen M, Helakorpi S, Rahkonen O, Uutela A \& Prättälä R (2007) Trends of socioeconomic differences in daily vegetable consumption, 1979-2002. Eur J Clin Nutr 62, 823-833.

14. Kamphuis CB, Giskes K, de Bruijn GJ, Wendel-Vos W, Brug J \& van Lenthe FJ (2006) Environmental determinants of 
fruit and vegetable consumption among adults: a systematic review. BrJ Nutr 96, 620-635.

15. Lahelma E, Martikainen P, Laaksonen M \& Aittomäki A (2004) Pathways between socioeconomic determinants of health. J Epidemiol Community Health 58, 327-332.

16. Food and Agriculture Organization of the United Nations (date not known) FAO Statistical Databases, Food Balance Sheets. http://faostat.fao.org/site/502/default.aspx (accessed March 2007).

17. Stapel S (2002) Eating, drinking, smoking - comparative price levels in EU, EFTA and candidate countries for 2001. Eurostat Statistics in Focus. Theme 2: Economy and Finance, vol. 42. Luxembourg: European Commission.

18. Mackenbach J, Stirbu I, Roskam A-J, Schaap MM, Menvielle G, Leinsalu M \& Kunst AE; European Union Working Group on Socioeconomic Inequalities in Health (2008) Socioeconomic inequalities in health in 22 European countries. N Engl J Med 358, 2468-2481.

19. Schaap M, Roskam A, Stirbu I \& Kunst A (2006) Specification of Data Files Created Within the EUROTHINE Project, Version 3.1. Rotterdam: Erasmus MC, University Medical Centre.

20. Mackenbach J, Stirbu I, Roskam A-J, Schaap M, Menvielle G, Leinsalu M \& Kunst A (2007) Socio-economic inequalities in mortality and morbidity: a cross-European perspective. In Tackling Health Inequalities in Europe: An Integrated Approach. EUROTHINE, Final Report, pp. 24-48. Rotterdam: Erasmus MC, University Medical Centre.

21. Grabauskas V, Klumbiene J, Petkeviciene J et al. (2007) Health Behaviour among Lithuanian Adult Population, 2006. Publication no. B7/2007. Helsinki: National Public Health Institute.

22. Gonzalez CA, Argilaga S, Agudo A et al. (2002) Diferencias sociodemográficas en la adhesión al patrón de dieta mediterránea en poblaciones de Espana. Gac Sanit 16 214-221.

23. Similä M, Fagt S \& Vaask S (2003) The NORBAGREEN 2002 Study. Consumption of Vegetables, Potatoes, Fruit, Bread and Fish in the Nordic and Baltic Countries. TemaNord 2003: 556. Copenhagen: Nordic Council of Ministers.

24. Giskes K, Turrell G, Patterson C \& Newman B (2002) Socioeconomic differences in fruit and vegetable consumption among Australian adolescents and adults. Public Health Nutr 5, 663-669.

25. Ovaskainen M-L, Paturi M \& FINDIET Study Group (2007) The diet of adults with socio-economical disadvantages in FINDIET 2002. Poster presented in the European Conference on Public Health (EUPHA), October 2007, Helsinki, Finland.

26. Dynesen AW, Haraldsdóttir J, Holm L \& Astrup A (2003) Sociodemographic differences in dietary habits described by food frequency questions - results from Denmark. Eur J Clin Nutr 57, 1586-1597.

27. Kim D \& Holowaty E (2003) Brief, validated survey instruments for the measurement of fruit and vegetable intakes in adults: a review. Prev Med 36, 440-447.

28. Tessier S \& Gerber M (2005) Factors determining the nutrition transition in two Mediterranean islands: Sardinia and Malta. Public Health Nutr 8, 1286-1292.

29. Prättälä R, Berg M-A \& Puska P (1992) Diminishing or increasing contrasts? Social class variation in Finnish food consumption pattern in 1979-1990. Eur J Clin Nutr 46, $279-287$.

30. Roos E, Prättälä R, Lahelma E, Kleemola P \& Pietinen P (1996) Modern and healthy?: socioeconomic differences in the quality of diet. Eur J Clin Nutr 50, 753-760. 